University of Puget Sound

Sound Ideas

All Faculty Scholarship

Faculty Scholarship

$4-1-2012$

\title{
Economic-based Projections Of Future Land Use In The Conterminous United States Under Alternative Policy Scenarios
}

Volker C. Radeloff

Department of Forest and Wildlife Ecology, University of Wisconsin, 1630 Linden Drive, Madison, Wisconsin 53706 USA

E. Nelson

Economics Department, Bowdoin College, 9700 College Station, Brunswick, Maine 04011 USA

Andrew J. Plantinga

Department of Agricultural and Resource Economics, Oregon State University, Corvallis, Oregon 97331-3601 USA

David J. Lewis

University of Puget Sound, djlewis@pugetsound.edu

D. Helmers

Department of Forest and Wildlife Ecology, University of Wisconsin, 1630 Linden Drive, Madison, Wisconsin 53706 USA

See next page for additional authors

Follow this and additional works at: http://soundideas.pugetsound.edu/faculty_pubs

\section{Citation}

Radeloff, Volker C., E. Nelson, Andrew J. Plantinga, David J. Lewis, et al. 2012. "Economic-based projections of future land use in the conterminous United States under alternative policy scenarios." Ecological Applications 22(3): 1036-1049.

This Article is brought to you for free and open access by the Faculty Scholarship at Sound Ideas. It has been accepted for inclusion in All Faculty Scholarship by an authorized administrator of Sound Ideas. For more information, please contact soundideas@pugetsound.edu. 
Authors

Volker C. Radeloff, E. Nelson, Andrew J. Plantinga, David J. Lewis, D. Helmers, J. J. Lawler, J. C. Withey, F. Beaudry, Sebastian Martinuzzi, V. Butsic, E. Lonsdorf, D. White, and Stephen Polasky 


\title{
Economic-based projections of future land use in the conterminous United States under alternative policy scenarios
}

\author{
V. C. Radeloff,${ }^{1,10}$ E. Nelson, ${ }^{2}$ A. J. Plantinga, ${ }^{3}$ D. J. Lewis,${ }^{4}$ D. Helmers, ${ }^{1}$ J. J. Lawler,${ }^{5}$ J. C. Withey, ${ }^{5}$ \\ F. Beaudry, ${ }^{6}$ S. Martinuzzi,${ }^{1}$ V. Butsic, ${ }^{1}$ E. Lonsdorf, ${ }^{7}$ D. White,${ }^{8}$ and S. Polasky ${ }^{9}$ \\ ${ }^{1}$ Department of Forest and Wildife Ecology, University of Wisconsin, 1630 Linden Drive, Madison, Wisconsin 53706 USA \\ ${ }^{2}$ Economics Department, Bowdoin College, 9700 College Station, Brunswick, Maine 04011 USA \\ ${ }^{3}$ Department of Agricultural and Resource Economics, Oregon State University, Corvallis, Oregon 97331-3601 USA \\ ${ }^{4}$ Economics Department, University of Puget Sound, 1500 North Warner Street, Tacoma, Washington 98416 USA \\ ${ }^{5}$ School of Forest Resources, University of Washington, Box 352100, Seattle, Washington 98195 USA \\ ${ }^{6}$ Environmental Studies Department, Alfred University, 1 Saxon Drive, Alfred, New York 14802 USA \\ ${ }^{7}$ Urban Wildlife Institute, Conservation and Science, Lincoln Park Zoo, Chicago, Illinois 60614 USA \\ ${ }^{8}$ Department of Geosciences, Oregon State University, Corvallis, Oregon 97331 USA \\ ${ }^{9}$ Department of Applied Economics, University of Minnesota, 1994 Buford Avenue, St. Paul, Minnesota 55108 USA
}

Abstract. Land-use change significantly contributes to biodiversity loss, invasive species spread, changes in biogeochemical cycles, and the loss of ecosystem services. Planning for a sustainable future requires a thorough understanding of expected land use at the fine spatial scales relevant for modeling many ecological processes and at dimensions appropriate for regional or national-level policy making. Our goal was to construct and parameterize an econometric model of land-use change to project future land use to the year 2051 at a fine spatial scale across the conterminous United States under several alternative land-use policy scenarios. We parameterized the econometric model of land-use change with the National Resource Inventory (NRI) 1992 and 1997 land-use data for 844000 sample points. Land-use transitions were estimated for five land-use classes (cropland, pasture, range, forest, and urban). We predicted land-use change under four scenarios: business-as-usual, afforestation, removal of agricultural subsidies, and increased urban rents. Our results for the business-asusual scenario showed widespread changes in land use, affecting $36 \%$ of the land area of the conterminous United States, with large increases in urban land (79\%) and forest (7\%), and declines in cropland $(-16 \%)$ and pasture $(-13 \%)$. Areas with particularly high rates of landuse change included the larger Chicago area, parts of the Pacific Northwest, and the Central Valley of California. However, while land-use change was substantial, differences in results among the four scenarios were relatively minor. The only scenario that was markedly different was the afforestation scenario, which resulted in an increase of forest area that was twice as high as the business-as-usual scenario. Land-use policies can affect trends, but only so much. The basic economic and demographic factors shaping land-use changes in the United States are powerful, and even fairly dramatic policy changes, showed only moderate deviations from the business-as-usual scenario. Given the magnitude of predicted land-use change, any attempts to identify a sustainable future or to predict the effects of climate change will have to take likely land-use changes into account. Econometric models that can simulate land-use change for broad areas with fine resolution are necessary to predict trends in ecosystem service provision and biodiversity persistence.

Key words: econometric modeling; ecoregions; ecosystem services; forest; land-use change; land-use scenarios; net returns; urban growth.

\section{INTRODUCTION}

Land-use change arguably exerts the single largest human impact on the environment (Vitousek et al. 1997, Foley et al. 2005). Land-use change has significantly contributed to biodiversity declines (Sala et al. 2000, Tilman et al. 2001, Ehrlich and Pringle 2008), via habitat loss and fragmentation (Fahrig 2003, Radeloff et al.

Manuscript received 25 February 2011; revised 16 August 2011; accepted 17 October 2011; final version received 15 December 2011. Corresponding Editor: X. Xiao.

${ }^{10}$ E-mail: radeloff@wisc.edu 2005a, b), invasive species spread (Gavier-Pizarro et al. $2010 a, b$ ), carbon release into the atmosphere (Dixon et al. 1994, Rhemtulla et al. 2009), altered water cycles (Carpenter et al. 1998, Stevenson and Sabater 2010), and the loss of ecosystem services (Schroter et al. 2005, Tscharntke et al. 2005). Given the large environmental impacts of land use and the potential for large land-use changes in the future, policies and actions aimed toward a more sustainable future will require a thorough understanding of how policies can affect land-use patterns as well as how changes in extent and pattern of land use affect both ecosystem service provision and 
biodiversity persistence. Our ability to predict future land-use change at scales that are ecologically meaningful, however, is limited.

Approaches that predict land-use change that are spatially detailed enough to be ecologically meaningful include simple Markov models based on historical landuse change and rule-based approaches (Pontius et al. 2008). These approaches start with a map of current land cover, such as a satellite land cover classification (e.g., Vogelmann et al. 2001, Homer et al. 2004). Transitions in land cover in each pixel in future time steps are based either on past land-use trends (Lambin 1997), the spatial neighborhood of each pixel (Lakes et al. 2009), or a desired or predicted land cover abundance at a broader scale (Sohl and Sayler 2008).

However, the limitations of these common spatially detailed land-use models is that they do not explain transitions as a function of human decision making, and often lack data about the economic incentives driving those decisions (Turner et al. 2007). For example, consider the Conservation Reserve Program, which pays farmers to plant marginal cropland with permanent vegetative cover (e.g., Lubowski et al. 2006, 2008). A farmer's decision to participate in such a program would depend on the economic returns to various land uses, which are only partly explained by landscape features. Land-use models that do not incorporate economic returns directly and that lack an underlying economic theory of landowner decision making cannot simulate incentive-based scenarios realistically, severely limiting their ability to assess policy outcomes (Capozza and Helsley 1989, Bockstael 1996).

Econometric land-use models that are based on observed landowner decision making can be used to map expected land-use change in response to projected changes in economic conditions and landscape features (Lewis and Plantinga 2007, Towe et al. 2008). Econometric models measure the explicit relationship among land-use allocations and the inherent productivity of the land as determined by biophysical features, returns to improvement of the land, society's preferences for various goods, and policies that manipulate economic returns. In doing so, econometric models can be used to simulate future land-use changes as a function of the net returns of different land uses and the costs resulting from switching from one land-use type to another, which are often the key underlying drivers of land-use change.

Unfortunately, econometric models of land-use change face many of the issues of scale that also hamper ecological models. On the one hand studies with large extents (e.g., a state or country) are often parameterized with coarse-grain data (e.g., at the county level) and the results may be inappropriate for management applications at sub-county scales, or when results need to be summarized for other spatial units. On the other hand, studies that use fine-grain spatial data (e.g., pixels) are typically limited to small extents (e.g., a landscape) and therefore may not be informative to processes that take place at larger scales (e.g., national governmental subsidies). What is needed, and what we propose here, is a large-extent, fine-grain, econometric model of landuse change.

Most of the scale issues related to econometric models are the result of data limitations. Most socioeconomic variables are collected for administrative units rather than grid cells, making it more straightforward to apply the econometric models at the same administrative scale (e.g., Plantinga 1996, Hardie and Parks 1997). Furthermore, some economic data only makes sense at a coarse scale (e.g., commodity prices determined in national or global markets). However, a land-use-change model at a coarse spatial resolution has limited value for ecological assessments, given that most ecological processes of interest, such as habitat suitability, dispersal, and invasive species spread, operate at finer scales (Turner 1989). Furthermore, administrative boundaries rarely correspond to ecological boundaries, and this means that ecological conditions tend to vary substantially within each administrative unit, introducing further uncertainty to ecological assessments.

Thus there is a need for econometric models of landuse change and the question is what type of econometric model can best provide fine-grained predictions. The unit of analysis is a major difference among land-use model. The two major types are plot-based models, and parcel-based models, and there are important trade-offs among these two types. A parcel of land refers to a piece of contiguous land owned by a single entity, and can comprise multiple plots of homogeneous quality land. The advantage of plot-based models is that they can be estimated for very large areas, because consistent plotbased data on land-use change is available, e.g., in the United States from the National Resources Inventory (NRI) or the Forest Inventory Analysis (FIA) databases (available online). ${ }^{1,12}$ Several such fine-scale econometric land-use models have been estimated (e.g., Lubowski et al. 2006, Lewis and Plantinga 2007, Plantiga et al. 2007). These models translate plot-level observations of land-use change into probabilistic estimates that a certain land-use type will transition into another class. Fine-grained covariates, such as soil quality, a predictor of a site's inherent productivity, can also enter these models, as long as that information is available for most sampled units. Econometric models can also incorporate information measured or meaningful at spatial scales coarser than plot level, such as county-level net returns to different land uses (Lubowski et al. 2006) or state- or national-level economic policies. Once a plot-levelchange model has been estimated, it can be used to predict plot-level change, or if a wall-to-wall prediction is desired, pixel-level change, as long as the plot-level variables used to explain the estimated model are also

\footnotetext{
11 http://www.nrcs.usda.gov/technical/NRI/

12 http://www.fia.fs.fed.us/
} 
available for the land units where future land use is to be simulated. However, a shortcoming of plot-based models is that they commonly ignore neighborhood effects. For example, a pixel that is forested and surrounded by agriculture is more likely to transition to agriculture itself, than a forested pixel that is surrounded by forest. Unfortunately, both NRI and FIA data provide information for single locations only, and lack information about the immediate neighborhood of these locations (plots).

More realistic simulation of fine-scale spatial patterns is the strength of parcel-level models, which are typically estimated from parcel-level data derived from localized sources such as county land information offices (e.g., Irwin and Bockstael 2002, Newburn and Berck 2006, Lewis et al. 2009). Given that most parcel-level data sets can capture neighborhood effects, econometric models estimated from such data tend to incorporate much greater spatial detail. However, the shortcoming of parcel-level models is that parcel-level data sets tend to be available only for small areas, and models estimated from such data are incapable of incorporating broadscale factors that do not vary within small regions (e.g., timber and crop prices). Thus both plot- and parcelbased models have their strengths and weaknesses, but for large areas, plot-based models are typically the only feasible option.

In a few cases, spatially explicit econometric land-use models have been coupled with biophysical models to predict ecosystem service and biodiversity provision under alternative landscape conditions. For example, biodiversity values, carbon stocks, and commodity production levels in the Willamette Basin of Oregon, USA differ considerably among management scenarios when examined with plot-level methods (Polasky et al. 2005, Nelson et al. 2008, Polasky et al. 2008, Lewis 2010). Similarly, in northern Wisconsin, a parcel-level econometric model of housing development was coupled with lake ecosystem models and showed the effects of zoning policies on green frog populations (Lewis et al. 2009) and ecological indicators of lake ecosystems (Butsic et al. 2010).

To our knowledge, spatially explicit econometric land-use models with fine spatial resolution have so far only been conducted for single ecoregions (e.g., for the prairie pothole region by Rashford et al. [2011]) and not at the national scale. In general, spatially explicit econometric land-use models that cover broad geographical areas are desirable for several reasons. First, many ecological processes of interest can only be understood when analyzing large regions (e.g., nutrient loading into the Gulf of Mexico due to agricultural practices in the upper Midwest of the United States). Second, regional estimates of ecosystem or biodiversity provision will be biased if the provision is affected by land-use patterns outside of the region. Finally, many incentive-based policies that affect land-use decision making are applied to either entire states or entire nations. Assessing such policies for selected regions only and then extrapolating to all regions in a state or nation is inappropriate if the sampled landscapes are not representative of the rest of the state or nation.

The overarching goal of this research was to develop methods to predict future land-use patterns across the United States at a spatial resolution that is suited for ecological assessments of alternative land-use policies. Our objectives here were to (1) develop spatially explicit models that can predict land use in 2051 for the entire conterminous United States at sub-county resolution, and (2) evaluate the impacts of alternative policy scenarios on future land-use patterns.

\section{Methods}

Our land-use projections were based on an econometric model that explained observed land-use changes at the plot level from 1992 to 1997 as a function of expected net returns to various land uses and the costs of converting from one land use to another. Net returns are a function of land parcel characteristics (e.g., soil quality and location), commodity prices, and production costs. However, net returns are also affected by policies, such as agricultural subsidies or payments for provision of ecosystem services, and this is how we can use the model to evaluate the effects of these policies on future landuse patterns.

Four different policies were compared, including (1) a "business-as-usual" baseline scenario, (2) an afforestation scenario that increased net returns to forestry, (3) a removal of certain agricultural subsidies scenario, and (4) an increased urban land value scenario. The increased urban land value scenario was not reflective of a specific policy and instead was meant to mimic a future where population increase creates a higher than expected demand for urban and suburban housing. These four scenarios explore a range of future policy, economic, and demographic conditions, and highlight how these conditions could affect land use.

\section{The econometric land-use model}

Our econometric model was estimated with USDA Natural Resources Inventory (NRI) data. The NRI data reports land use for 844000 sampled private land plots throughout the United States (Nusser and Goebel 1997) and we used data from 1992 and 1997 to estimate the model parameters. The land-use categories used in the econometric estimation are crops, pasture, forest, urban, Conservation Reserve Program, and range. Though the exact locations of the NRI plots are not revealed for privacy reasons, county location and plot characteristics are available. This information is sufficient to estimate land-use change probabilities for every county and land capability class (an integrated measure of soil quality and agricultural potential; USDA 1973).

The econometric estimation is described in detail in Lubowski et al. (2006). Multinomial logit models were estimated for each starting use (crops, pasture, etc.) in 
order to explain the observed choice of remaining in the same use or choosing one of the other uses. Specifically, the estimation procedure identifies the parameters $(\beta)$ in the function $p_{i j k}=F\left(\boldsymbol{\beta}_{j k} \mathbf{X}_{i}\right)$ where $p_{i j k}$ is the probability that parcel $i$ changes from use $j$ to use $k$ between 1992 and $1997, \boldsymbol{\beta}_{j k}$ is a vector of parameters associated with the $j$-to- $k$ transition, and $\mathbf{X}_{i}$ is a vector of independent variables for plot $i$. The independent variables included in the $\mathbf{X}$ vector were a site's current land use, estimated per-acre county-level net returns to each of the land uses modeled, and the site's land capability class rating. County-level net returns are defined as the average annual profit (revenues less costs) observed in the county from each land use. In the case of crops, the net return includes federal agricultural subsidies. The net returns data was provided by Lubowski et al. (2006). The basis for our policy simulations are changes in the variables in $\mathbf{X}_{i}$, which produces changes in the land-use transition probabilities (see Alig et al. [2010] for a related application).

The results from the econometric estimation specify probabilistic land-use transition matrices for each county and each land capability class. Initially, each land-use transition matrix provides transition probabilities for a single 5-year time step (corresponding to the 1992-1997 interval). By applying matrix multiplication, we derived 50-year transition probability matrices (specifically, if $\mathbf{M}$ is the 5-year transition matrix, then $\mathbf{M}^{10}$ is the 50-year matrix). Each element of the 50-year matrix equals the probability that a parcel starting in use $j$ will end in use $k$ after 50 years, accounting for all possible transition paths from use $j$ to $k$ over the 50 -year period. Land-use transitions were permitted among all land-use classes, the only exception being "urban": urban areas do not revert to other land-use types because the NRI data did not show any transitions out of urban use. In addition, we kept current land cover on publicly owned land constant (as mapped by the Protected Areas Database; available online). ${ }^{13}$

\section{Landscape data}

We used spatial data sets of current land cover and LCC to generate the starting values for the 50-year landuse simulation. Current land cover was derived from the 2001 National Land Cover Classification (NLCD; Homer et al. 2004). The 2001 NLCD is a $30-\mathrm{m}$ resolution satellite image classification based on Landsat TM and ETM+ imagery. The 2001 NLCD provides information on more land cover classes than the NRI. We therefore grouped the NLCD classes into forest (NLCD classes 41, deciduous forest; 42, coniferous forest; and 43, mixed forest), agriculture (82, cultivated crops), pasture (81, pasture/hay), range (51, shrubland and 71 , grasslands/herbaceous), and urban (21, 22, 23, and 24, developed). Water, wetland, and barren NLCD

\footnotetext{
$13 \mathrm{http}: / /$ databasin.org/protected-center
}

classes (11, open water; 12 , perennial ice/snow; 31 , bare rock/sand/clay; 90, woody wetlands; and 95, emergent herbaceous wetland) were not included in transitions and remained static.

Land-use decisions are typically made for spatial units larger than the $30-\mathrm{m}$ pixels of the 2001 NLCD data. We aggregated the 2001 NLCD into $100 \times 100 \mathrm{~m}(1 \mathrm{ha})$ pixels using a majority rule, to simulate the spatial equivalent of landownership parcels. One-hectare parcels were chosen as a compromise that is still meaningful for urban areas, where land-use parcels tend to be smaller than 1 ha, and agricultural and forest land use, where land-use parcels tend to be larger. However, we note that actual units of land-use change likely exhibit a range of sizes below and above 1 ha, and our choice of 1 ha pixels as units of analysis will have affected the spatial patterns of the resulting maps. We also note that the use of NLCD land cover data as a starting point for an NRI land-use-based simulation is potentially problematic. For example, a forest that was recently cut would still be classified as forest land use in the NRI, but as shrub in the NLCD. However, the lack of a detailed land-use data set for the United States necessitated using the NLCD instead.

To map the land capability class nationwide, we used the Soil Survey Geographic (SSURGO) database (USDA National Resources Conservation Service; available online). ${ }^{14}$ In some counties, only a small number of NRI points were available for some of the eight LCC classes. This is why we reclassified SSURGO's eight non-irrigated capability classes into four classes (1-2 was reclassified as 1, 3-4 became 2, and so on), thereby increasing sample sizes in each of the resulting four classes so that we had sufficient sample sizes for the econometric estimations.

Following the approach of Lewis and Plantinga (2007), we then simulated land-use change stochastically, based on the fitted 50-year transition probabilities. Actual land-use transitions are simulated by comparing the probability value with a random number between zero and one. If, for example, a cropland pixel has a $10 \%$ chance of transitioning to forest and also a $10 \%$ chance of transitioning to urban, then a random number between 0 and 0.1 would result in a land-use change to forest, a number between 0.1 and 0.2 to a change to urban, and any larger number in a continued use as cropland. A single set of random numbers (one for each pixel) will result in a single land-use projection. This process is repeated 500 times, generating a new land-use projection each time, to account for stochastic variability.

\section{Policy and price scenarios}

We evaluated the potential implications of four policy scenarios that affect landowner land-use decision

14 http://soils.usda.gov/survey/geography/ssurgo/ 
making. These scenarios were selected to highlight the kind of scenarios that can be simulated, and we discuss the limitations of the scenarios and our modeling approach in detail in Discussion. The first scenario was a business-as-usual scenario where we used the estimated transition matrices produced by the econometric model to simulate pixel-level land use 50 years into the future across the country. This scenario also served as a baseline against which we compared the other policy scenarios. The other three scenarios implemented policies that altered the county-level net returns for certain land-use types. We re-calculated the transition matrices with the altered county-level net returns to predict 2051 land use under these alternative policy scenarios. The three scenarios were selected to simulate dramatic policy interventions to show the extent to which incentive-based policies might affect future landuse trajectories.

In the afforestation scenario, we considered a US\$247.11/ha (\$100/acre) subsidy for afforestation and a US\$247.11/ha (US\$100/acre) tax on deforestation. Under this policy a landowner would be given the subsidy if they transitioned from any non-forest land use to a forested land use and taxed if they transitioned from a forested land use to any non-forest land use. Such a policy could be motivated, for example, by a desire to increase carbon sequestration. Based on results in Lubowski et al. (2006), this translates into a carbon tax/subsidy of about $\$ 50 /$ metric ton of carbon. These incentives were introduced into the econometric model by increasing the net return to forestry for transitions into forest and reducing the net return to forestry for transitions out of forest.

In the removal of certain agricultural subsidies scenario, all direct subsidies to farmers, as they existed during the early 1990s, were eliminated. For the most part, these subsidies were federal price supports, payments made to farmers when the price for major grains, and a few other agricultural products, fell below a certain threshold. Other forms of subsidies to farmers, such as the payments under the Conservation Reserve Program, were not altered in this scenario. Removal of the direct subsidies reduced the net returns to cropland. On average, direct payments represented approximately $11 \%$ of county net returns to cropland in the United States during the 1990s. There was, however, significant regional variation in this percentage, from about $2 \%$ in the New England states to between $15 \%$ and $20 \%$ in the Plains states.

Finally, in the urban growth scenario, we increased net returns to urban land use by $25 \%$ in all counties. This scenario is consistent with recent historical changes in urban returns. County net returns to urban land increased in the United States by $36 \%$, on average, between 1987 and 1997 and by 29\%, on average, between 1977 and 1987 (Lubowski 2002). During these two 10 -year periods, the U.S. population is estimated to have increased by $13 \%$ and $10 \%$, respectively.

\section{Summaries of baseline and alternative scenarios land-use change}

We summarize land-use change under each scenario using the mean 2051 map (i.e., the expected land-use change given each scenario's transition matrices). While our econometric model predicts land-use in each pixel as of 2051, because our model does not incorporate localscale processes affecting land-use patterns (such as zoning, idiosyncratic landowner preferences, and microclimate), we have more confidence in broader regional summaries of land-use change than predictions of change for individual pixels (see Discussion). For each class of land use, we summarized net change, as well as total loss (all areas that transitioned out of a given land use), total gain (all areas that transitioned into a given land use), and total change (i.e., total gains plus total loss). Area estimate of loss, gain, and total change of each land-use class were converted into percentages, by dividing them by the total area in 2001 .

One major advantage of our approach was that the simulation at $100-\mathrm{m}$ resolution allowed summarizing future land-use change for any spatial unit of interest, without being limited by the boundaries of administrative units such as counties or states. We summarized predicted land use for Omernik's ecoregions to show results on a more ecologically meaningful unit of analysis. These summaries were conducted at two scales (ecoregion level II and III; available online). ${ }^{15}$

Last, we examined land-use change in detail for the North Central Hardwood Forests ecoregion. The purpose was to highlight the spatial detail and the potential limitations of our predictions at fine scales. We selected this ecoregion because they included areas of abundant land-use change, and because we were familiar with land-use patterns given our prior work (Radeloff et al. 2005a, Lewis et al. 2010). Land-use change was summarized in 500-ha hexagons to visualize areas with fine-grained land-use change. We recorded the percentage of the area of each hexagon in each land-use class in both 2001 and 2051, as well as the change in the percentage.

\section{Results}

Our simulations under the business-as-usual scenario suggested that land use in the conterminous United States will likely change profoundly by 2051 (Figs. 1 and 2). The business-as-usual scenario predicted that about $36 \%$ of the area of the conterminous United States will change land use over the 50-year period from 2001 to 2051. Two land-use types predicted to increase are urban and forest (Fig. 2a). Urban is projected to be the fastest growing land use both in terms of its rate of increase ( $79 \%$ vs. $7 \%$ for forest), and in terms of the area increase (33 vs. 14 million hectares). Crops, pasture, and range are all projected to decline. Crops are projected to

15 http://www.epa.gov/wed/pages/ecoregions.htm 
decline the most in relative terms $(-16 \%)$, and in absolute terms ( -20 million hectares).

Net changes reflect only a small portion of the total land-use change (Fig. 2a, b). In the case of pasture, for example, the net change was only a 7.3 million hectare loss $(-8 \%)$. However, of the 56 million hectares of pasture in 2001, 38 million or $69 \%$ were projected to transition to another land use, but there will also be 31 million hectares of new pasture (55\% gain) on areas that were in crop (19 million), forest (4 million), or range (9 million) in 2001.

Our model assumed that all land-use transitions involving urban represented gains in urban area (Fig. $2 b)$. The largest portions of the total urban gain of 33 million hectares are from forest (13 million) and crop (9 million). Range exhibited the opposite tendency than urban land, as the majority of its land-use change involved losses. The 26 million hectares of total losses were fairly evenly split among the four other land-use classes, with loss to pasture being the largest (9 million) and loss to urban being the smallest (4.5 million).

The removal of agricultural subsidy scenario and the business-as-usual scenario predicted virtually the same amounts of the total area changed $(36 \%)$. These two scenarios predicted slightly higher total land-use change than the urban growth scenario (34\%), and considerably less than the forest price scenario (40\%, Fig. 2c). This general pattern also applied to changes of individual land cover classes: the business-as-usual and removal of agricultural subsidy scenarios were virtually identical, and the high urban scenario very similar to those two. Only the afforestation scenario showed appreciatively different land-use trends (Fig. 2c).

In the afforestation scenario, the net change in forest became larger than the net change in urban (40 million vs. 32 million hectares, Fig. 2d). The increase in forest land was largely at the expense of cropland and range. Cropland and range declined by 38 and 26 million hectares, respectively, in the afforestation scenario, vs. 20 and 19 million hectares, respectively, in the businessas-usual scenario. However, because forest area in 2001 was about five times larger than urban area (207 million vs. 41 million hectares), urban still had a larger gain in the afforestation scenario ( $78 \%$ for urban vs. $19 \%$ for forest).

Land-use changes varied considerably among ecoregions (Fig. 3). At the coarser level II ecoregions, pasture was predicted to decline throughout large portions of the eastern United States, but increase in the West. The finer level III ecoregions showed that forest areas along the Appalachian crest were predicted to decline, a pattern that was missing in the coarser level II ecoregions. We checked the robustness of both the level II and level III ecoregion predictions, by comparing averages for subsets of our 500 simulations with those for the full set, and found that averages for more than 200 replicates were almost identical to those for the full 500 replicates (results not shown). Given the robustness
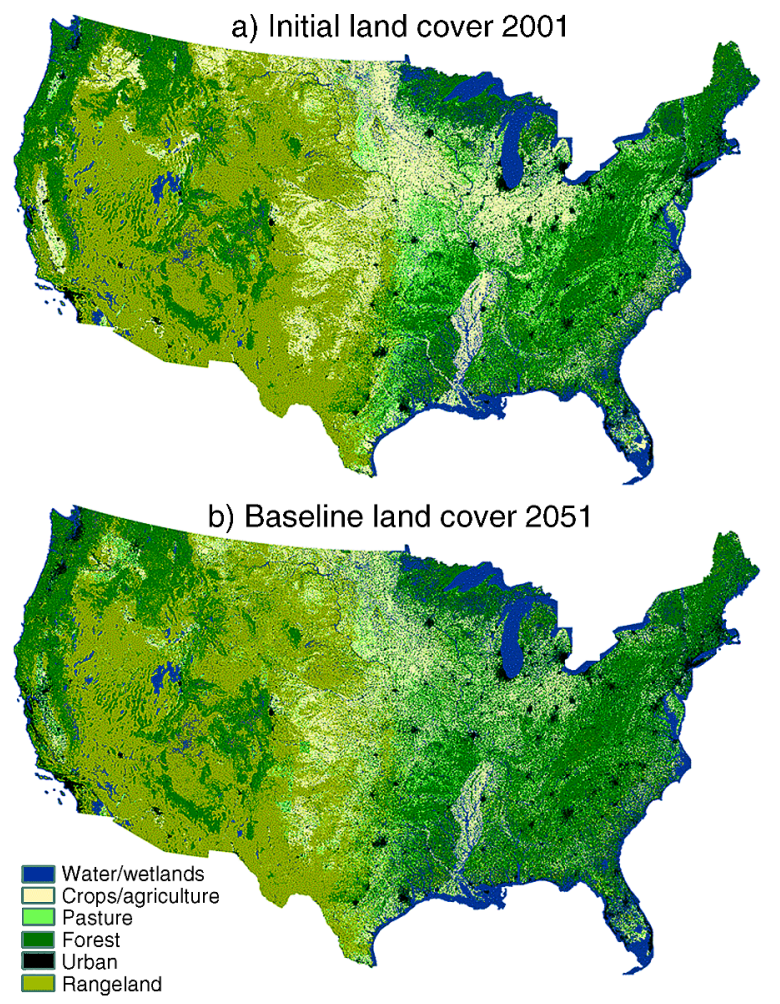

FIG. 1. (a) Land-use patterns in 2001 and (b) land-use projections for 2051 according to one randomly selected replicate of our business-as-usual baseline scenario.

of our level III ecoregion results, we decided to focus reporting results at this scale rather than the coarser level II ecoregion scale. Among all level III ecoregions, the ecoregions with the largest percent area projected to change in land-use in the baseline scenario included the Central Corn Belt Plains of northern Illinois and parts of Indiana surrounding Chicago, parts of the Pacific Northwest, and the Central Valley of California (Fig. 4). In these areas, more than half of the area was predicted to change in land use. In contrast, the Intermountain West, the desert Southwest, and parts of the South were predicted to be fairly stable, with land-use changes less than $20 \%$ of their area.

As was true at the national level, the results for the level III ecoregion summaries showed little difference between the business-as-usual scenario and the removal of agricultural subsidies scenario (Fig. 5). Differences between business-as-usual and increased urban rent scenario were also small, but the increased urban rent scenario had more urban growth occurring in the lower Midwest, the northwestern Great Plains and the Intermountain West. More notable, however, were the differences between the afforestation scenario and all the other scenarios. The afforestation scenario predicted much more forest, especially in the western Great Plains and the Intermountain West, paired with strong declines in crops in the same areas and in Illinois and Indiana, 

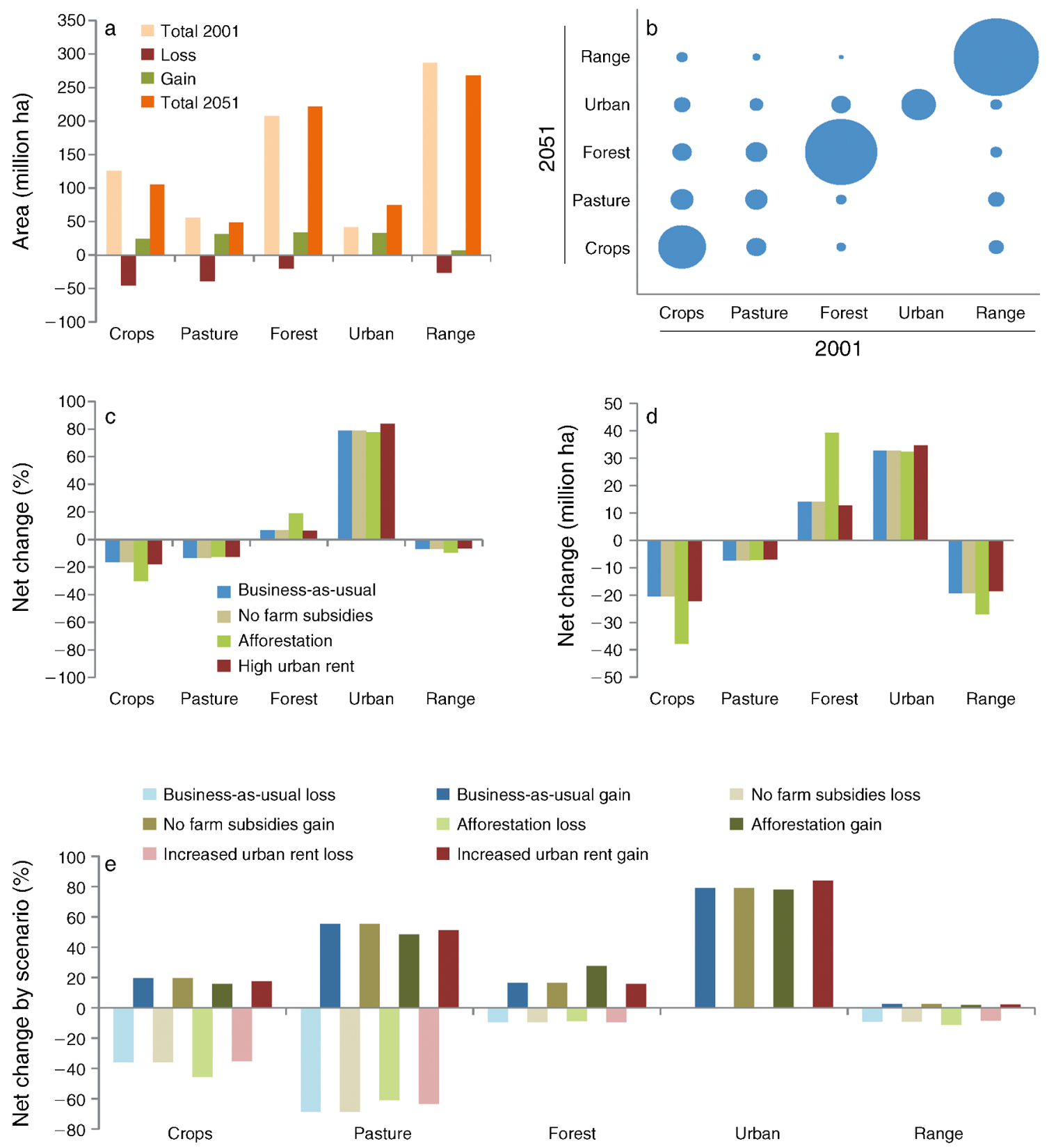

FIG. 2. (a) The area of each land-use class in 2001 and its gains, losses, and estimated area in 2051 under the baseline scenario. (b) Transitions among the five land cover classes under the baseline scenario. The area of the circles is proportional to the area that changed (e.g., constant rangeland was 263 million hectares). (c) The percentage net change of each land-use class, (d) the net change of each land-use class in hectares, and (e) net gains and losses of each land-use class under each of the four scenarios.

and marked declines in rangeland throughout the Great Plains. Interestingly though, patterns of pasture loss for the afforestation scenario were very similar to the other three scenarios.

Finally, we examined the predicted land use for the four scenarios in more detail for the North Central Hardwood Forests (Fig. 6). In the North Central Hardwoods under the business-as-usual scenario, urban land was predicted to gain 565711 ha on top of the
707135 ha that existed in 2001. Pasture was projected to lose 501598 ha of the 1279285 ha that existed in 2001.

Differences among the policy scenarios were minor. The predicted increase in urban area was $88 \%$ under the increased urban rent scenario vs. $80 \%$ for the businessas-usual scenario. The increased urban rent and afforestation scenarios led to higher losses of pasture but these results were similar to the business-as-usual scenario (516 009 ha loss under the increased urban rent 


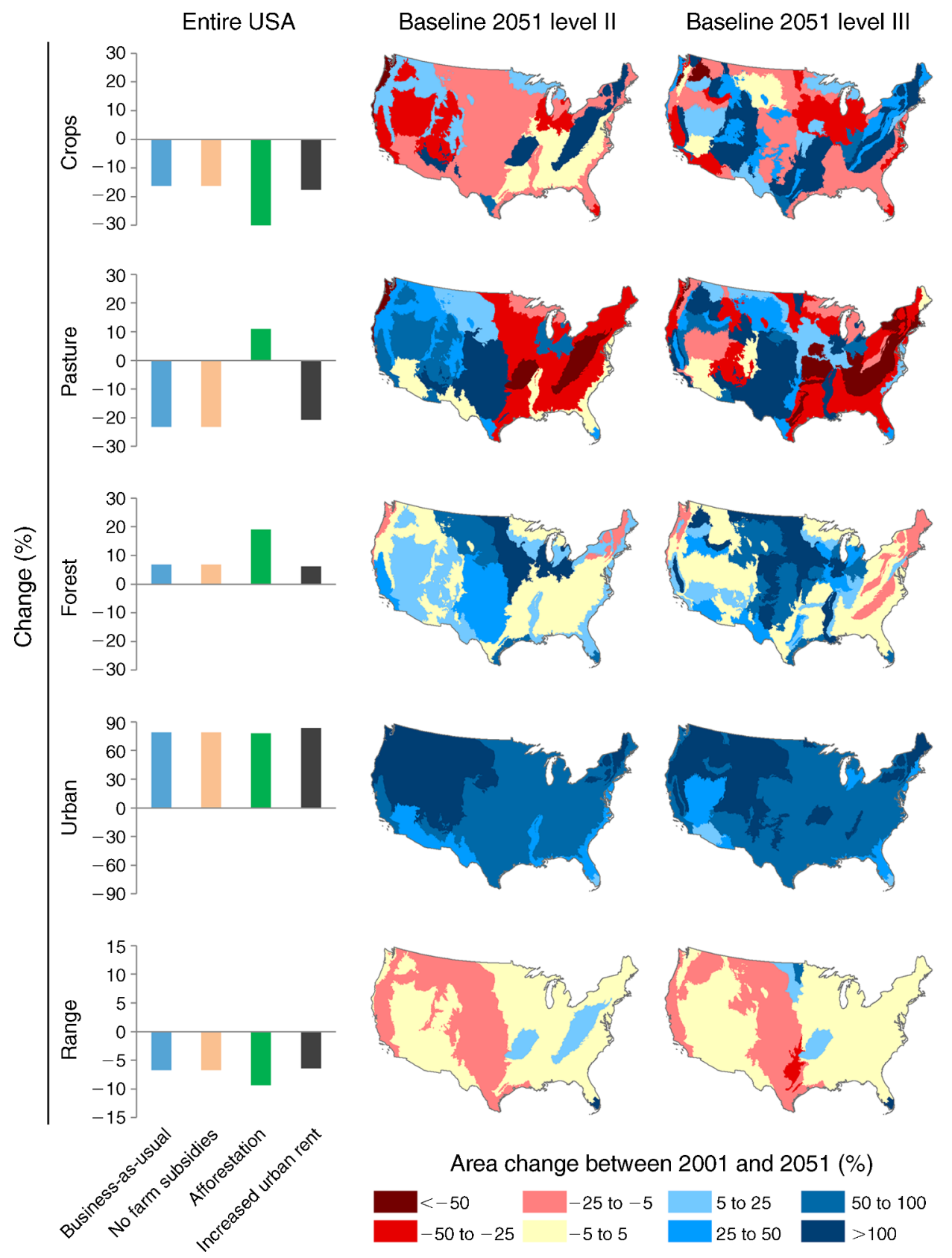

FIG. 3. Percentage change of the area of different land-use types (rows) in the entire United States (bar graphs in the column on the left), the coarser level II ecoregions (middle column), and the finer level III ecoregions (right column).

scenario vs. 501598 ha under the business-as-usual scenario).

\section{Discussion}

Our predictions of future land use in the United States suggest that large changes in land use are likely in the upcoming decades if land-use trends prevalent during the 1990 s continue, even in the face of broad policy changes. The analysis projects substantial movement in multiple directions (e.g., forest-to-crops and crops-to- forest) such that total land-use change is greater than net change for all non-urban uses. All four scenarios predicted substantial declines in crops, pasture, and range, and a substantial increase in urban area. The scenarios predicted medium to strong increases in forest land depending on the scenario. In general, changes in the East were more pronounced than changes in the West, but other than the desert Southwest, land use in all parts of the United States were projected to change substantially. Altogether, our land-use projections were 


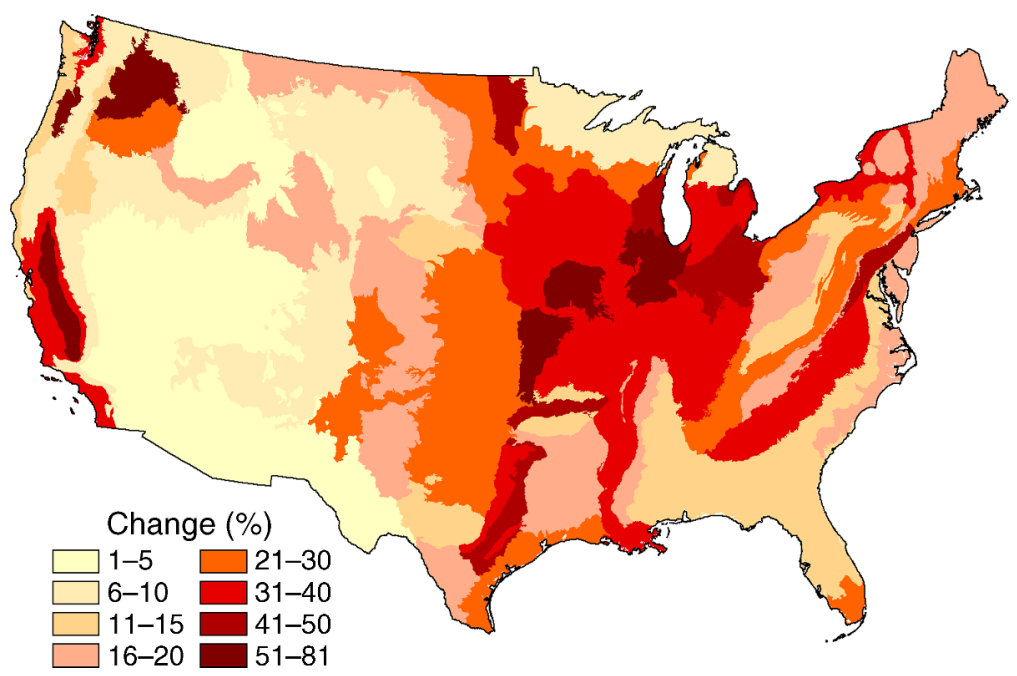

FIG. 4. The percentage of each level III ecoregion projected to change in land use by 2051 under the baseline scenario.
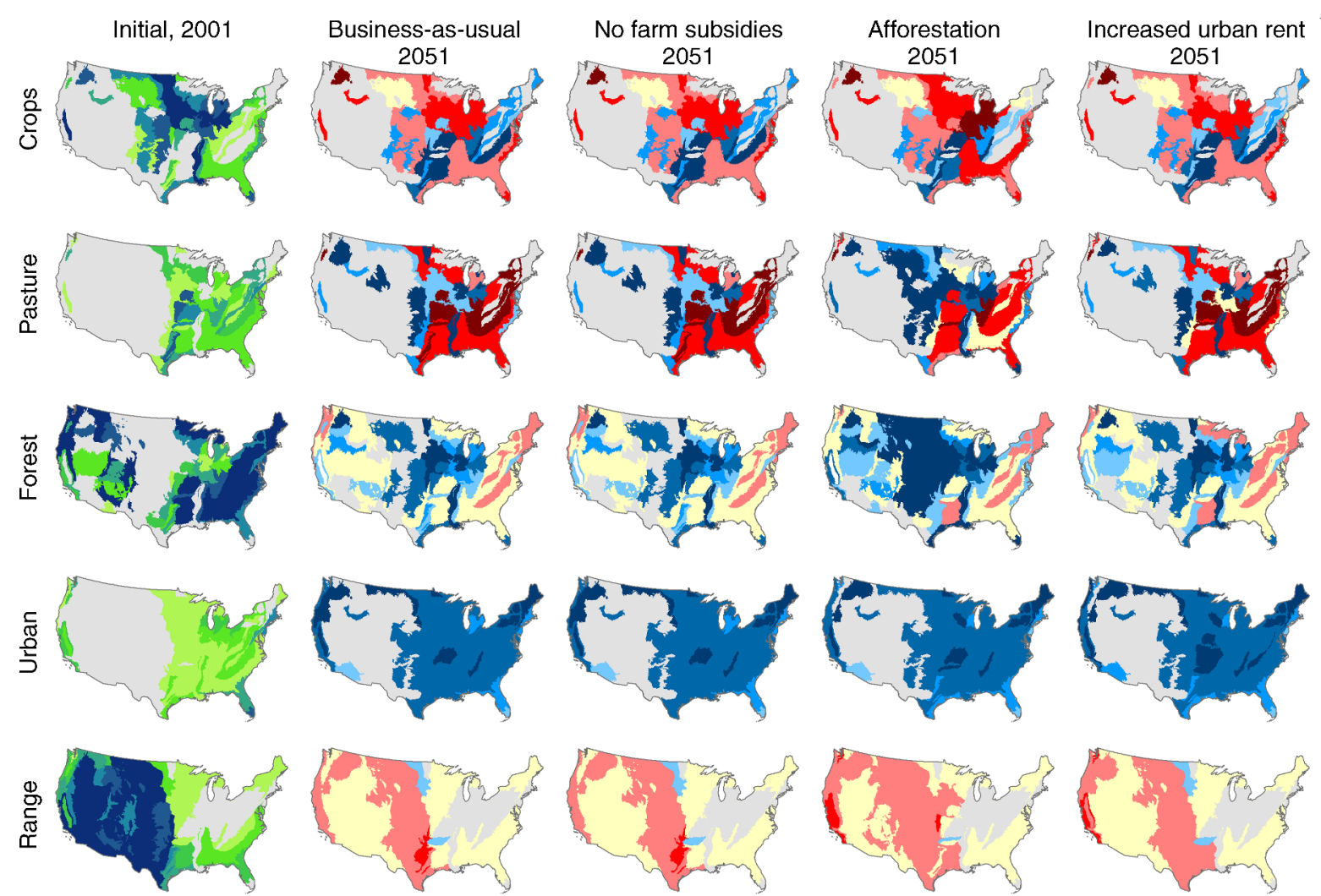
Area $(\%)$
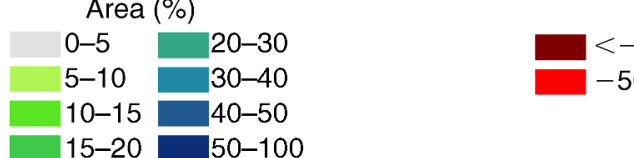

Area change between 2001 and 2051 (\%)

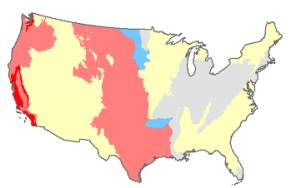

50 to 100

50 to $-25 \quad-5$ to 5

5 to 25

$>100$

FIG. 5. Net gains and losses (percentage) for each land use class under each land-use scenario. 


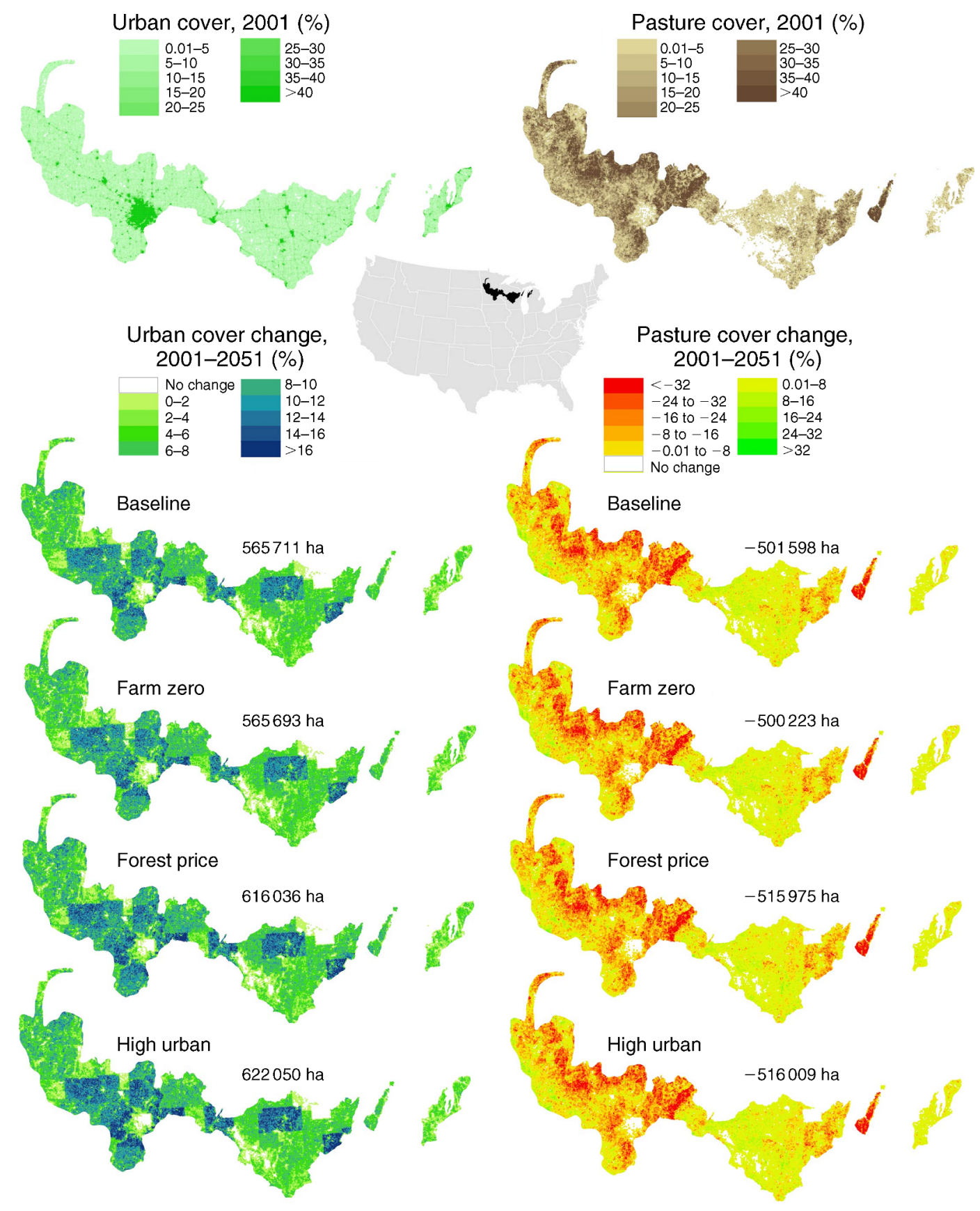

FIG. 6. Change in urban and pasture land use from 2001 to 2051 in the level III ecoregion North Central Hardwood Forests in one randomly selected replicate of each scenario. Values on each panel are the area gained or lost.

in close agreement with other recent studies forecasting major urban expansion (Radeloff et al. 2010), relatively small change in total forest land area (Alig et al. 2003), and strong regional variations in future land-use change (e.g., Wear and Greis 2002, Tyrrell et al. 2004, Sohl and Sayler 2008).

While predicted changes in land use were substantial, the differences between our four scenarios were not, which was somewhat surprising. The comparison of our four land-use scenarios highlighted that even fairly dramatic policy interventions may have only limited power to change the predicted trends in land-use change. It was not surprising that urban areas are projected to increase substantially, especially since the econometric model was estimated with data for a period (1992-1997) of remarkable urban growth. However, it surprised us that increasing urban rents substantially, or changing returns in other uses (forestry or agriculture), did not 
substantially alter the rates of urbanization. Upon reflection, this result is probably due to the fact that net returns from urban development are much higher than all other land uses near urban areas, but drop off quickly in areas far from urban centers. There may be some ability of local authorities to channel growth in urban areas through use of zoning and conservation easements, but there appears to be little scope for limiting overall the growth of urban areas via land-use taxes or subsidies, at least within the range of policies simulated here.

Similarly, the decline in pastureland was fairly uniform across the four scenarios. Here, the reasons for stability of results across scenarios are probably the opposite from that described for urban areas. Land rents for pasture are very low and any pasture that has the opportunity to transition to another more profitable land use will probably transition. Pasture land is typically land that is not high value for crops, forest, or urban and so will remain pasture as long as other opportunities are not present. Our model projected fairly minor net losses overall, but large shifts both into and out of pasture. However, it is unlikely that incentive-based policies - at least those that are similar to ones we analyzed - will have much of an effect on pasture lands.

The land-cover type that was most sensitive to the policy tools we simulated was forest. Forest is predicted to increase under all four scenarios. However, the urban growth scenario predicted only about one-third of the increase in forest land that the afforestation scenario predicted. The predicted increase of almost 39 million hectares of forest under the afforestation scenario is also the highest increase for any land cover class under any policy scenario. For those interested in encouraging carbon sequestration or other ecosystem services related to forests, these results are encouraging because they suggests that policies can be put in place to substantially increase forest area.

Among the four policy tools, the afforestation scenario resulted in the biggest differences in land use as compared to the business-as-usual scenario. In contrast, the removal of agricultural subsidies had virtually no effect on landuse patterns. The fact that the business-as-usual and the removal of agricultural subsidies scenarios were virtually identical highlights two important points about future land-use change in the United States. First, land in the agricultural belt of the United States that is at risk for conversion to urban use will convert with or without subsidies. Returns from urban use at the edge of expanding urban areas are so dominant that even subsidized cropland returns cannot compete on the urban-rural interface. Second, croplands that are not at the urban-rural interface are likely to remain in cropland even with reduced subsidies. In these areas there are no reasonable alternatives to cropland use (this assumes no other policies like the afforestation policy have been implemented as well). Finally, these results highlight that, for cropland not projected to convert to urban use, changes in returns to agricultural prices could affect crop choice and cropland management but will not necessarily affect overall land-use patterns.

\section{Limitations of our econometric land-use model}

Our results are fairly robust, and consistent with past land-use simulations (Lubowski et al. 2006, Alig et al. 2010), but it is important to keep in mind that they are based on models, and any model is by definition a simplification of reality. That means that the results from our models can only be used within certain limits, and one important limitation is the scale at which our results are meaningful. While we modeled land-use change for 1-ha pixels, we do not suggest that our results are meaningful at the single-pixel scale, and the 1-ha pixel size represented a compromise. Especially in intensive crop areas, land-use parcels can be considerably larger than 1 ha, whereas land-use change in urban areas may occur in parcels that are smaller. When we examined our land-use predictions in detail, we found that some patterns, especially those of urban growth showed marked differences along county borders in some parts of the United States (Fig. 6). This may reflect to some extent differences in zoning and growth policies among counties, but it is more likely a model artifact.

For example, in the Wisconsin portion of the North Central Hardwoods, one county (Marathon County) stands out as having exceptionally high urban growth rates. It is likely that within Marathon County, urban land will be more concentrated around the city of Wausau in the center of the county. One reason why our prediction suggest that the entire county will witness high growth is that land-use transitions from other land uses into urban are uniform for a given soil type within a given county. In other words, if the soil class is the same, then a forest pixel right next to an existing urban area is as likely to change to urban as a forest pixel far away from any other urban areas. Our econometric model did not incorporate neighborhood effects that are typical for urban growth, and these neighborhood effects matter little when results are aggregated to ecoregions, but this example highlights the spatial limitations of our results. The second reason is that differences among soil types affect urban land use the least of all the land-use types. For pasture, differences among soil type are more important, and as a result, the predictions of future pasture land do not exhibit the artifacts along county boundaries. We also note that the effects of county boundaries were less pronounced in other parts of the country where the land capability class was more variable within the county, thus capturing within-county land-use change patterns better (results not shown).

An area for future research is thus the development of data and methods that can be incorporated in, or combined with, econometric models to account for determinants of land-use decisions at fine spatial scales. Ultimately, the lack of realistic fine-scale patterns is not 
an inherent limitation of econometric models. However, data limitations are the main reason why, to date, econometrically modeling fine-scale spatial effects has only been done with richly detailed parcel data sets for small regions such as U.S. counties (e.g., Irwin and Bockstael 2002, Newburn and Berck 2006, Lewis et al. 2009), and not at the national scale. New data sets, such as the Land Cover Trends Data (Drummond and Loveland 2010) may overcome these data limitations though. And new modeling approaches, such as FORESCE (Sohl and Sayler 2008), could be used to allocate the projected land cover proportions spatially to provide more realistic patterns of land-use change.

Second, our three land-use scenarios used in addition to the baseline were not selected to reflect policies that are necessarily likely to be implemented in the future. Rather, these four scenarios were selected to highlight the kind of scenarios that can be simulated by econometric models and to assess the extent to which policies might be able to affect land use. As such, the goal was not to make realistic predictions about land use in 2051, and we caution that any land-use prediction over such a length of time (i.e., 50 years) is inherently fraught with uncertainty since changes in technology, institutions, and societal values cannot be predicted. A related issue is that our models were parameterized with NRI land use from 1992 to 1997. Our models would thus propagate any unusual land-use patterns during that period into the future, and that could have resulted unrealistic projections for some regions.

Third, our models were not dynamic. Changes in landuse mean that the supply of related commodities will change over time as well. As commodities become more or less scarce their market price will rise and costs of production will change, but our model does not account for these changes, and did not include endogenous prices and costs. For example, if forest area expands under the afforestation scenario at the cost of agricultural land, then increasing prices for agricultural products would raise land rent for agriculture, and both make further afforestation less likely and conversion of other land use to agriculture more likely. A related shortcoming was that we extrapolated observed reactions to economic conditions that existed in the mid 1990s. If land owners begin to react differently to economic signals in the future, then such an extrapolation will produce erroneous results. For example, if a new generation of American farmers develops a stronger land sustainability ethic, then our models will imperfectly predict future behavior, and econometric models like ours are not well suited to simulated changes in attitudes and cultures, which also affect land-use decisions. Similarly, if future population and housing growth patterns deviate substantially from those during the 1990s, which were a decade of high housing growth, then our projections would be biased as well.

Fourth, if biophysical conditions in all or parts of the United States change dramatically, then our extrapola- tions will be off. For example, most returns to land use are directly or indirectly affected by climate. If climate changes substantially over the next 50 years, the range of reasonable land-use choices available to landowners in various parts of the United States will be different than the reasonable choices landowners faced in the same region a generation earlier. A related issue is that, while the NRI did record land-use transition toward more forested use in the western Great Plains and selected sites, such as riparian areas, may support tree growth, the general biophysical conditions may not support afforestation. A worthwhile extension of our model may thus be to add biophysical data to restrict tree growth where it is not possible.

Last but not least, our model accounted only for land use, not land management. Many ecosystem services and biodiversity attributes are highly sensitive to land management choices. For example, organic farming has a very different impact on the environment than conventional farming techniques. Similarly, we assumed that public lands would not change their land use, but land management is likely to change in the future, and that could have important ramifications. Modeling of land management choices and the policies that affect these choices was missing from our methodology.

\section{Conclusions}

Despite these limitations, our goal to develop methods to predict future land use with an econometric model for a large area with fine spatial resolution was successfully met, and the model led to interesting results. Our approach projected land-use change as a function of observed human (economic) behavior to allocate predicted changes in land use (e.g., allocating urban sprawl across space based on expected changes in population, population density, and past observed spatial patterns of urban spread). Our approach was spatially comprehensive (e.g., it covered the whole country, not just areas near cities), and operated at the parcel scale and not a county, state, or regional scale, which means that the grain of our model was similar to the spatial scale at which land owners decide upon land use. Finally, because we modeled land-use change as a function of net returns, we were able to analyze a number of relevant policy levers (e.g., changes in prices, yields, costs), which highlighted the extent to which the policy levers can, or cannot, affect the extent of different land uses. As such, our approach represents a major step forward toward the analysis of coupled human-natural systems, and opens new research avenues to examine the ecological implications of different land-use policies for large areas, at a resolution that allows for realistic ecological predictions.

\section{ACKNOWLEDGMENTS}

We gratefully acknowledge support for this research from the National Science Foundation's Coupled Natural-Human Systems Program. We are also grateful for comments from two anonymous reviewers, which greatly improved our manuscript. 


\section{Literature Cited}

Alig, R. J., A. J. Plantinga, S. Ahn, and J. D. Kline. 2003. Land use changes involving forestry in the United States: 1952 to 1997, with projections to 2050. General Technical Report PNW-GTR-587. U.S. Department of Agriculture, Forest Service, Pacific Northwest Research Station, Portland, Oregon, USA.

Alig, R. J., A. J. Plantinga, D. Haim, and M. Todd. 2010. Area changes in U.S. forests and other major land uses, 1982 to 2002, with projections to 2062. General Technical Report PNW-GTR-815. U.S. Department of Agriculture, Forest Service, Pacific Northwest Research Station, Portland, Oregon.

Bockstael, N. E. 1996. Modeling economics and ecology: the importance of a spatial perspective. American Journal of Agricultural Economics 78:1168-1180.

Butsic, V., D. J. Lewis, and V. C. Radeloff. 2010. Lakeshore zoning has heterogeneous ecological effects: an application of a coupled economic-ecological model. Ecological Applications 20:867-879.

Capozza, D. R., and R. W. Helsley. 1989. The fundamentals of land prices and urban-growth. Journal of Urban Economics 26:295-306.

Carpenter, S. R., N. F. Caraco, D. L. Correll, R. W. Howarth, A. N. Sharpley, and V. H. Smith. 1998. Nonpoint pollution of surface waters with phosphorus and nitrogen. Ecological Applications 8:559-568.

Dixon, R. K., S. Brown, R. A. Houghton, A. M. Solomon, M. C. Trexler, and J. Wisniewski. 1994. Carbon pools and flux of global forest ecosystems. Science 263:185-190.

Drummond, M. A., and T. R. Loveland. 2010. Land-use pressure and a transition to forest-cover loss in the Eastern United States. BioScience 60:286-298.

Ehrlich, P. R., and R. M. Pringle. 2008. Where does biodiversity go from here? A grim business-as-usual forecast and a hopeful portfolio of partial solutions. Proceedings of the National Academy of Sciences USA 105:11579-11586.

Fahrig, L. 2003. Effects of habitat fragmentation on biodiversity. Annual Review of Ecology Evolution and Systematics 34:487-515.

Foley, J. A., et al. 2005. Global consequences of land use. Science 309:570-574.

Gavier-Pizarro, G. I., V. C. Radeloff, S. I. Stewart, C. D. Huebner, and N. S. Keuler. 2010a. Housing is positively associated with invasive exotic plant species richness in New England, USA. Ecological Applications 20:1913-1925.

Gavier-Pizarro, G. I., V. C. Radeloff, S. I. Stewart, C. D. Huebner, and N. S. Keuler. 2010b. Rural housing is related to plant invasions in forests of southern Wisconsin, USA. Landscape Ecology 25:1505-1518.

Hardie, I. W., and P. J. Parks. 1997. Land use with heterogeneous land quality: an application of an area base model. American Journal of Agricultural Economics 79:299310 .

Homer, C., C. Huang, L. Yang, B. Wylie, and M. Coan. 2004. Development of a 2001 National Landcover Database for the United States. Photogrammetric Engineering and Remote Sensing 70:829-840.

Irwin, E. G., and N. E. Bockstael. 2002. Interacting agents, spatial externalities and the evolution of residential land use patterns. Journal of Economic Geography 2:31-54.

Lakes, T., D. Mueller, and C. Krueger. 2009. Cropland change in southern Romania: a comparison of logistic regressions and artificial neural networks. Landscape Ecology 24:11951206.

Lambin, E. F. 1997. Modelling and monitoring land-cover change processes in tropical regions. Progress in Physical Geography 21:375-393.
Lewis, D. J. 2010. An economic framework for forecasting land-use and ecosystem change. Resource and Energy Economics 32:98-116.

Lewis, D. J., and A. J. Plantinga. 2007. Policies for habitat fragmentation: combining econometrics with GIS-based landscape simulations. Land Economics 83:109-127.

Lewis, D. J., B. Provencher, and V. Butsic. 2009. The dynamic effects of open-space conservation policies on residential development density. Journal of Environmental Economics and Management 57:239-252.

Lubowski, R. N. 2002. Determinants of land-use transitions in the United States: Econometric analysis of changes among the major land-use categories. Dissertation. Harvard University, Cambridge, Massachusetts, USA.

Lubowski, R. N., A. J. Plantinga, and R. N. Stavins. 2006. Land-use change and carbon sinks: econometric estimation of the carbon sequestration supply function. Journal of Environmental Economics and Management 51:135-152.

Lubowski, R. N., A. J. Plantinga, and R. N. Stavins. 2008. What drives land-use change in the United States? A national analysis of landowner decisions. Land Economics 84:529550 .

Nelson, E., S. Polasky, D. J. Lewis, A. J. Plantingall, E. Lonsdorf, D. White, D. Bael, and J. J. Lawler. 2008. Efficiency of incentives to jointly increase carbon sequestration and species conservation on a landscape. Proceedings of the National Academy of Sciences USA 105:9471-9476.

Newburn, D. A., and P. Berck. 2006. Modeling suburban and rural-residential development beyond the urban fringe. Land Economics 82:481-499.

Nusser, S. M., and J. J. Goebel. 1997. The National Resources Inventory: a long-term multi-resource monitoring programme. Environmental and Ecological Statistics 4:181-204.

Plantinga, A. J. 1996. The effect of agricultural policies on land use and environmental quality. American Journal of Agricultural Economics 78:1082-1091.

Plantinga, A. J., R. J. Alig, H. Eichman, and D. J. Lewis. 2007. Linking land-use projections and forest fragmentation analysis. Research Paper PNW-RP-570. U.S. Department of Agriculture, Forest Service, Pacific Northwest Research Station, Portland, Oregon, USA.

Polasky, S., et al. 2008. Where to put things? Spatial land management to sustain biodiversity and economic returns. Biological Conservation 141:1505-1524.

Polasky, S., E. Nelson, E. Lonsdorf, P. Fackler, and A. Starfield. 2005. Conserving species in a working landscape: land use with biological and economic objectives. Ecological Applications 15:1387-1401.

Pontius, R. G., Jr., et al. 2008. Comparing the input, output, and validation maps for several models of land change. Annals of Regional Science 42:11-37.

Radeloff, V. C., R. B. Hammer, and S. I. Stewart. 2005a. Rural and suburban sprawl in the US Midwest from 1940 to 2000 and its relation to forest fragmentation. Conservation Biology 19:793-805.

Radeloff, V. C., R. B. Hammer, S. I. Stewart, J. S. Fried, S. S. Holcomb, and J. F. McKeefry. 2005b. The wildland-urban interface in the United States. Ecological Applications 15:799-805.

Radeloff, V. C., S. I. Stewart, T. J. Hawbaker, U. Gimmi, A. M. Pidgeon, C. H. Flather, R. B. Hammer, and D. P. Helmers. 2010. Housing growth in and near United States protected areas limits their conservation value. Proceedings of the National Academy of Sciences USA 107:940-945.

Rashford, B. S., J. A. Walker, and C. R. Bastian. 2011. Economics of grassland conversion to cropland in the Prairie Pothole Region. Conservation Biology 25:276-284.

Rhemtulla, J. M., D. J. Mladenoff, and M. K. Clayton. 2009. Historical forest baselines reveal potential for continued carbon sequestration. Proceedings of the National Academy of Sciences USA 106:6082-6087. 
Sala, O. E., et al. 2000. Global biodiversity scenarios for the year 2100. Science 287:1770-1774.

Schroter, D., et al. 2005. Ecosystem service supply and vulnerability to global change in Europe. Science 310:13331337.

Sohl, T. L., A. L. Gallant, and T. R. Loveland. 2004. The characteristics and interpretability of land surface change and implications for project design. Photogrammetric Engineering and Remote Sensing 70:439-448.

Sohl, T., and K. Sayler. 2008. Using the FORE-SCE model to project land-cover change in the southeastern United States. Ecological Modelling 219:49-65.

Stevenson, R. J., and S. Sabater. 2010. Understanding effects of global change on river ecosystems: science to support policy in a changing world. Hydrobiologia 657:3-18.

Tilman, D., J. Fargione, B. Wolff, C. D'Antonio, A. Dobson, R. Howarth, D. Schindler, W. H. Schlesinger, D. Simberloff, and D. Swackhamer. 2001. Forecasting agriculturally driven global environmental change. Science 292:281-284.

Towe, C. A., C. J. Nickerson, and N. Bockstael. 2008. Commonly requested conservation finance figures. American Journal of Agricultural Economics 90:613-626.

Tscharntke, T., A. M. Klein, A. Kruess, I. Steffan-Dewenter, and C. Thies. 2005. Landscape perspectives on agricultural intensification and biodiversity - ecosystem service management. Ecology Letters 8:857-874.

Turner, B. L., II, E. F. Lambin, and A. Reenberg. 2007. The emergence of land change science for global environmental change and sustainability. Proceedings of the National Academy of Sciences USA 104:20666-20671.

Turner, M. G. 1989. Landscape ecology - the effect of pattern on process. Annual Review of Ecology and Systematics 20:171-197.

Tyrrell, M. L., M. H. P. Hall, and R. N. Samlpon. 2004. Dynamic models of land use change in northeastern USAdeveloping tools, techniques, and talents for effective conservation action. GISF Research Paper 003. Program on Private Forests, Yale University, New Haven, Connecticut, USA.

USDA. 1973. National soil survey handbook, title 430-VI. U.S. Department of Agriculture, Natural Resources Conservation Service, Washington, D.C., USA. http://soils.usda.gov/ technical/handbook/

Vitousek, P. M., H. A. Mooney, J. Lubchenco, and J. M. Melillo. 1997. Human domination of Earth's ecosystems. Science 277:494-499.

Vogelmann, J. E., S. M. Howard, L. M. Yang, C. R. Larson, B. K. Wylie, and N. Van Driel. 2001. Completion of the 1990s National Land Cover Data set for the conterminous United States from Landsat Thematic Mapper data and Ancillary data sources. Photogrammetric Engineering and Remote Sensing 67:650-622.

Wear, D. N., and J. G. Greis, editors. 2002. Southern forest resource assessment. General Technical Report SRS-53. U.S. Department of Agriculture, Forest Service, Southern Research Station, Asheville, North Carolina, USA. 